\title{
Microwave and Ultrasound-Assisted Extraction of Capsaicinoids From Chili Peppers (Capsicum annuum L.) in Flavored Olive Oil
}

\author{
Antonello Paduano $^{1 *}$, Nicola Caporaso ${ }^{1 *}$, Antonello Santini ${ }^{2} \&$ Raffaele Sacchi ${ }^{1}$ \\ ${ }^{1}$ Department of Agriculture, University of Napoli “Federico II", Via Università 100 80055, Portici (Napoli), \\ Italy \\ ${ }^{2}$ Department of Pharmacy, University of Napoli “Federico II", Via D. Montesano 49 80131, Napoli, Italy \\ Correspondence: Nicola Caporaso, Food Science and Technology Unit, Department of Agriculture, University of \\ Naples Federico II, Via Università 100, Parco Gussone Ed. 84, 80055 Portici (NA), Italy. Tel: 39-081-253-9320. \\ E-mail: nicola.caporaso3@unina.it \\ *The authors contributed equally to this work.
}

Received: June 10, 2013 Accepted: December 10, 2013 Online Published: April 10, 2014

doi:10.5539/jfr.v3n4p51 URL: http://dx.doi.org/10.5539/jfr.v3n4p51

\begin{abstract}
The extraction of flavoring compounds from different plants and aromatic herbs has been using since ancient times in vegetable oils to enhance their aroma and taste, whereas the technology of production has changed over time. Our work aimed to evaluate alternative technologies for the production of aromatized olive oil such as ultrasound- and microwave-assisted extraction in comparison to traditional infusion or maceration of dried red hot chili pepper ( $10 \% \mathrm{w} / \mathrm{v}$ for 7 days). For the ultrasonic treatment, samples of olive oil were prepared by adding $10 \%$ and $20 \%$ dried chili pepper and subjected to ultrasound-extraction for 10 or 20 minutes. For microwave extraction, samples were added with $20 \%$ chili powder and treated for 10, 30 or 60 seconds. Capsaicinoids were quantified by HPLC-DAD directly in the flavored olive oil and antioxidant activity was evaluated by $\mathrm{ABTS}^{+}$ method. Capsaicinoids analysis in aromatized olive oil treated 20 minutes by ultrasound resulted about $130 \mathrm{ppm}$ (capsaicin and hydroxycapsaicin), when $10 \%$ chili powder was used, while it was $250 \mathrm{ppm}$ when $20 \%$ chili was used. The content of capsaicinoids extracted by traditional infusion was always higher for both concentrations of chili powder studied. The concentration of capsaicinoids in samples treated by microwaves extraction seem to be dependent on the treatment time, resulting 130 and $230 \mathrm{ppm}$ capsaicinoids for 10 and 60 seconds of treatment, respectively. In conclusion, the production of flavored olive oils by using technologies such as microwave and ultrasound-extraction could allow the production of high quality oils, with fast and cost-effectively methods.
\end{abstract}

Keywords: capsaicin, dihydroxycapsaicin, olive oil pungency, antioxidant activity, gourmet olive oil, red hot chili pepper, flavored olive oil, UV-HPLC analysis

\section{Introduction}

Flavored olive oil has been defined as an olive oil processed with vegetables, herbs, spices or fruits in order to improve its sensory characteristics (Baiano, 2009). Spices have historically been used by many cultures to enhance the flavor and aroma of foods. Their aroma is characterized by a wide range of volatile compounds, whose presence and quantity mainly depends on the spice used. Moreover, they have antioxidant (Yanishlieva et al., 2006) and antimicrobial (Souza et al., 2007) properties, and can be beneficial in the prevention of many human diseases such as breast, colon, and lung cancer (Kaefer \& Milner, 2008), and also thrombus formation (Yamamoto et al, 2005). The most interesting compounds showing positive health effects found in spices and herbs are phenolic compounds, terpenoids and derivatives of fatty acids or amino acids (Hirasa \& Takemasa, 1998). Essential oils in spices are complex mixtures of substances, ordinarily terpenes, sesquiterpenes and oxygenated derivatives, generally present at low concentrations (Lucchesi et al., 2004).

Spices can be added to foods in several forms: as whole spices, ground spices, essential oils or as oleoresins, or as prepared and filtered oil/vinegar infusions (Peter, 2001; Yamilka \& Jorge, 2011).

Extraction of oils and oleoresins from herbs and spices can be performed by using many methods, including: i) steam distillation, ii) hydrocarbon extraction, iii) chlorinated solvent extraction, iv) enzymatic treatment and fermentation, v) super critical carbon dioxide extraction (Peter, 2001). Conventional techniques for the extraction 
of active constituents are time and solvent consuming, thermally unsafe and the analysis of plant constituents is also limited by some extraction steps. These extraction techniques are mostly based on the use of solvents and heat or agitation to increase the solubility of the desired compounds and to improve the mass transfer (Mandal et al., 2007). In recent years, the use of alternative ways for the extraction of plant constituents has shown interest and potentialities both in research and industrial level. The Microwave Assisted Extraction (MAE) and Ultrasound Assisted Extraction (UAE) are relatively new extraction techniques that combine microwave and ultrasound treatments, respectively, with traditional solvent extraction. Both systems have been used for the extraction of natural compounds (e.g. polyphenolics, anthocyanins, aromatic compounds, polysaccharides and functional compounds) from different plant matrices, by varying the main parameters that may influence the extraction efficiency, namely the nature and volume of solvent, extraction time, microwave or ultrawaves power, matrix characteristics and temperature (Delazar et al., 2012; Vinatoru 2001; Vilkhu et al., 2008).

Olive oil is the most used fat in the Mediterranean countries, and it has been described as one of the most representative food in the so-called Mediterranean diet, associated to longevity and reduction of some cardio-vascular diseases. The notable positive properties on human health of olive oil has been mainly attributed to its fatty acid composition, particularly its high content in oleic acid, and to its phenolic compounds, which have been proved to exert interesting protective roles on humans.

Red-hot chili pepper (Capsicum annuum L.) is a popular spice used in many parts of the world and appreciated for its sensory attributes of color, pungency and aroma. The pungency of capsicum fruit is due to a group of compounds called capsaicinoids, which are reported in different concentration in Capsicum plants, depending on the variety, environment and agricultural practices (Korel et al., 2002).

The principle of Microwave Assisted Extraction is based on the application of microwaves for heating the solvents and plant tissues to accelerate the extraction process and to increase the kinetic of extraction. MAE has a number of advantages over traditional method of extraction, e.g., shorter extraction time, less need of solvent, higher extraction rate and lower cost. The use of MAE for the extraction of natural products started in the late 1980s and it has now become one of the most popular and cost-effective extraction methods through the technological developments. Several instrumentations and methodologies for MAE have become available, e.g., pressurized microwave-assisted extraction (PMAE) and solvent-free microwave-assisted extraction (SFMAE) (Delazar et al., 2012).

Ultrasound has been using in potential industrial application for the phyto-pharmaceutical extraction industry and food technology for a wide range of herbal extracts. The application of ultrasound as a laboratory-based technique for assisting extraction of plant material is widely reported in literature. In fact, several reviews have been published in the past years for the extraction of plant origin metabolites (Knorr, 2003), flavonoids from foods using a range of solvents (Zhang, Xu, \& Shi, 2003) and bioactives from herbs (Vinatoru, 2001). Despite the wide application of these two techniques for the solvent extraction of naturally occurring antioxidant compounds from plant tissues, few is known about the direct application of microwave and ultrasound treatment in the "direct extraction" by using vegetable oils as a solvent and thus avoiding the use of synthetic and unhealthy solvent and the subsequent need to dissolve the active compounds in the vegetable oil for its aromatization.

Thus, the aim of our work was to study the possibility to apply UAE and MAE for the extraction of dried chili pepper non-volatile compounds into olive oil to produce flavored olive oil, testing the extraction efficiency and the effect in terms of olive oil final quality.

\section{Materials and Methods}

\subsection{Standards and Reagents}

All chemicals used were of HPLC grade. The following chemical compounds were used as standards: natural capsaicin (capsaicin 65\% and dihydrocapsaicin 35\%), Trolox and $\mathrm{ABTS}^{+}$were purchased from Sigma-Aldrich (Steinheim, Germany), such as other chemicals used in our experiment.

\subsection{Samples and Flavored Olive Oils Production}

A commercial olive oil (mixture of virgin olive oil and refined olive oil) used for the experiments was donated by I.O.B.M. (Montesarchio, Benevento, Italy). Dried red hot chili pepper powder (Capsicum annuum) was purchased on the local market in Calabria region (Italy). Chili pepper flavored olive oils (CPOO) were prepared by infusion of chili pepper at different concentrations, 10 and $20 \%$ for 7 days maceration, as previously reported by Caporaso et al. (2013). 


\subsubsection{Microwave-Assisted Extraction}

Three samples of olive oil were used for the microwave treatment by adding $20 \%$ chili pepper, and subjected to microwave treatment for 10, 30 and 60 seconds, respectively. The microwave heating was carried out using a Microwaves Oven M500 (Philips S.p.A., Milano Italy), operating at a maximum power (500W).

\subsubsection{Ultrasound-Assisted Extraction}

Two concentration of chili pepper were used to produce flavored oils by adding $10 \%$ and $20 \%(\mathrm{w} / \mathrm{w})$ powdered chili pepper. The samples were subjected to ultrasound treatment for 10 and 20 minutes using a FALC UTA60 Ultrasonic Cleaner (Treviglio, BG, Italy), operating at a $28.5 / 31.5 \mathrm{kHz}$. All samples were prepared in triplicates ( 3 bottles, $100 \mathrm{~mL}$ each) and the analytical determinations were carried out on oil phase.

\subsection{Chemical Determinations}

\subsubsection{Quality Indices}

The analysis of the peroxide value $(\mathrm{PV})$ and the spectrophotometric indices $\left(\mathrm{K}_{232}, \mathrm{~K}_{270}, \Delta \mathrm{K}\right)$ were performed according to the European Official Methods of Analysis (EC Regulation 2568/91).

\subsubsection{HPLC Quantification of Capsacinoids}

The extraction of capsaicin from CPOOs and the UV-HPLC analysis was performed as previously reported by Caporaso et al. (2013). Capsaicin (65\% capsaicin and 35\% dihydrocapsaicin, SIGMA-Aldrich, Steinheim, Germany) was used as external standard for calibration curve $\left(\mathrm{R}^{2}=0.92\right)$. Identification of capsacinoids was performed by comparing their retention times and UV spectra to those of pure compounds.

\subsubsection{Antioxidant Activity by $\mathrm{ABTS}^{+}$Method}

ABTS analysis of flavored olive oil was performed according to the method reported by Re et al. (1999). Briefly, ABTS [2,2'-azino-bis(3-ethylbenzothiazoline-6-sulphonic acid)] (Sigma-Aldrich, Italy) was dissolved in $5 \mathrm{~mL}$ water to obtain a concentration of $7 \mathrm{mM}$. Then $88 \mu \mathrm{L}$ of a $2.45 \mathrm{mM}$ potassium persulfate solution was added to form the radical cation $\mathrm{ABTS}^{+}$. The mixture was stored in the dark at $4-6{ }^{\circ} \mathrm{C}$ for $12-16 \mathrm{~h}$ before use. The $\mathrm{ABTS}^{+}$ stock solution was diluted with ethanol to reach an absorbance of $0.70 \pm 0.02$ at $734 \mathrm{~nm}$ and at $25{ }^{\circ} \mathrm{C}$. Calibration curve was prepared using Trolox diluted in ethanol by using concentrations of 18, 36, 60, 90 and 120 $\mu \mathrm{M}$. The analysis was carried out after exactly 2.5 minutes of sample addition and the absorbance was read at $734 \mathrm{~nm}$ using a spectrophotometer mod. UV-1601 (Shimadzu Italia, Milan, Italy). For each dilution, the percentage of inhibition was calculated using the formula $A_{734} \%=\left(1-A_{f} / A_{0}\right) * 100$, where $A_{0}$ was the absorbance of blank sample and $A_{f}$ was the absorbance after $2.5 \mathrm{~min}$. The inhibition percentage was plotted as a function of concentration and the TAA (Total Antioxidant Activity) was calculated from the ratio of linear regression coefficient of the analyte and that of the Trolox. Results were expressed as mmol Trolox equivalents per kilogram oil (Re et al., 1999).

\subsubsection{Statistical Analysis}

The production of flavored olive oil and their treatment were performed in triplicate, and chemical analyses were carried out in triplicate. A two-way analysis of variance (ANOVA) was used to assess the effect of dried chili pepper concentration and the different treatments and extraction times, by using XLStat Version 6.1 software (Addinsoft, France). The differences were considered significant at $p<0.05$.

\section{Results and Discussion}

\subsection{Ultrasounds Extraction of Chili Pepper Compounds}

Capsaicinoids analysis in flavored olive oils obtained by using ultrasound-assisted extraction (UAE) showed that the amount of capsaicinoids (capsaicin and dihydrocapsaicin) was dependent on the concentration of added chili pepper powder, and on the time of ultrasound treatment, as expected (Figure 1). 

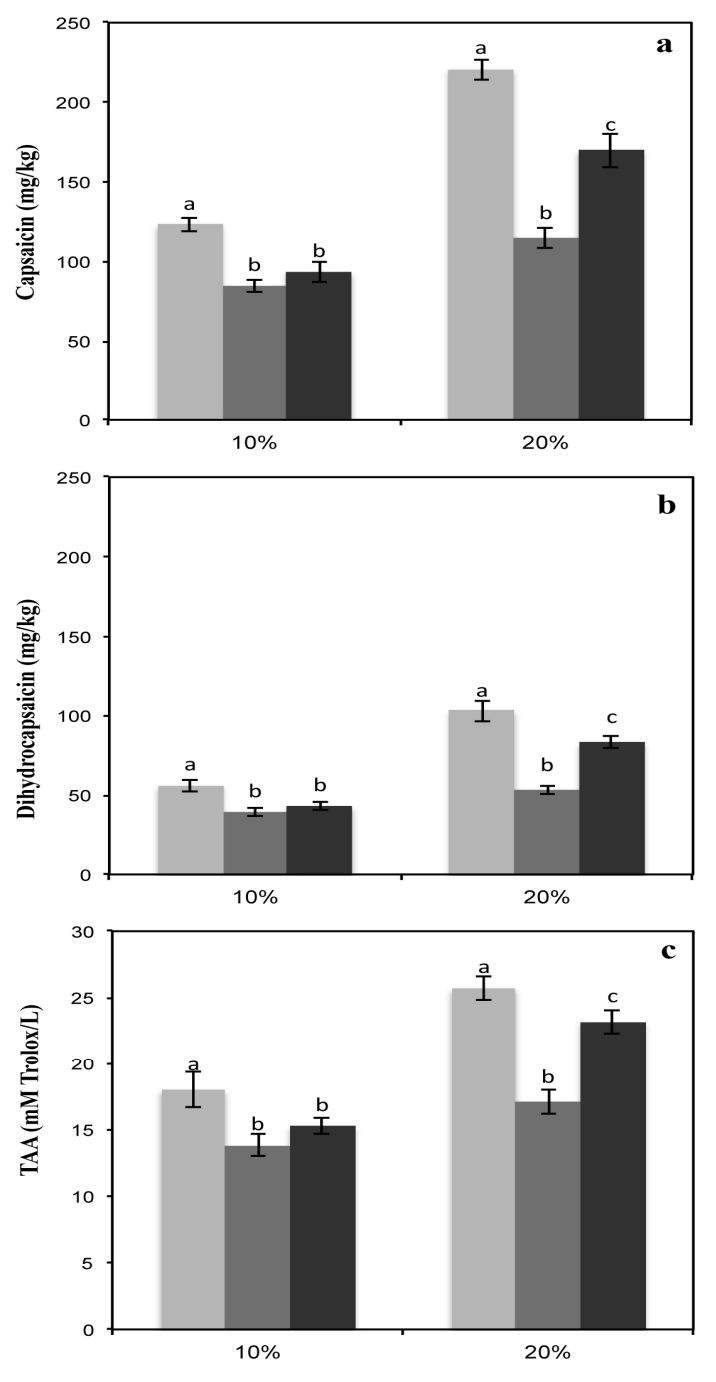

Figure 1. Capsaicin (a) and dihydrocapsaicin (b) content, and antioxidant activity (c) in chili pepper aromatized olive oil (CPOO) using different concentrations of chili pepper (10 and 20\%,w/w) and maceration times: 7 days traditional maceration (infusion), 10 and 20 minutes of ultrasound-assisted extraction

The content detected in UAE flavored oil was compared with that detected in the CPOO obtained by traditional chili pepper infusion for 7 days. This latter maceration time was chosen as it was previously described as the optimum time for the maximization of capsaicinoids extraction in the case of traditional maceration of chili pepper in olive oil (Caporaso et al., 2013). In Table 1 the amount of capsaicinoids (capsaicin and dihydrocapsaicin) extracted by using the ultrasound test was reported. A concentration of about $100 \mathrm{ppm}$ capsaicinoids was reached using a $10 \%$ of chili powder and about $200 \mathrm{ppm}$ using the concentration of $20 \%$, for samples treated for 20 minutes by UAM. The content of capsaicinoids extracted by means of 7 days traditional infusion was always higher for both concentrations of chili powder considered in our experiment (Figure 1).

Falleh et al. (2012) reported the application of an assisted-extraction procedure by using ultrasound, but the authors used methanol and ethanol for the extraction of polyphenols in various herbs and spices. As expected, longer treatment times caused higher increase in both capsaicinoids extraction and antioxidant activity. This result was in accordance with literature data about ultrasound-assisted extraction of plant bioactive compounds, e.g. Falleh et al. (2012) found a significant increase in total polyphenol contents and iron reducing activity, from 5 to 10 minutes of treatment. By using solvents, ultrasound treatment for $3 \mathrm{~h} \mathrm{had} \mathrm{better} \mathrm{performance} \mathrm{respect} \mathrm{to}$ maceration (15 h) and Soxhlet (5 h), and the extraction yield was also improved (Boonkird, Phisalaphong, \& Phisalaphong, 2008). The same authors reported that the solvent extraction was very fast during for the first 5 
minutes, probably for the effect of gradients from the chili pepper and the extraction phase.

As reported in our previously published paper (Caporaso et al., 2013), the direct application of HPLC on the flavored olive oil allowed quantifying the amount of capsaicinoids extracted. The method was very similar to that applied in the analysis of individual phenolic compounds of olive oil, thus it seems very interesting for a complete characterization of the non-volatile fraction of the vegetable oils, particularly olive oil and virgin olive oils. In our work, we used an olive oil, which is a blend of refined olive oil and virgin olive oil, and the natural amount of phenolic compounds ("biophenols") is very low. Further studies could use extra virgin olive oil, rich in phenolic compounds such as oleuropein derivatives, to also verify if interactions among some of these compounds and those released in the oil from Capsicum could occur.

Our approach, i.e. the direct aromatization of olive oil, was scarcely reported in literature at the moment. Viellet, Tomao and Chemat (2010) applied ultrasound assisted maceration by using basil. In this case, due to the specific composition of basil, the authors only evaluated the volatile composition of the aromatized olive oil.

Another example of the application of ultrasound-assisted extraction has been reported by Hossain et al. (2012) for marjoram. The authors applied Response Surface Methodology to assess the best extraction conditions of marjoram compounds, particularly phenolic compounds and they found a higher efficiency of ultrasound extraction respect to solid-liquid extraction. Many spices that are used in culinary applications have been reported in literature for the aromatization of vegetables oils, i.e. rosemary, marjoram, oregano, chili pepper, basil, thyme, etc., also due to their demonstrated potent antioxidant properties (Hossain et al., 2011). As reported by Hossain et al. (2011), traditional extraction methods as based on the use of solvents, and the liquid has to reaches high temperatures (up to $129-150{ }^{\circ} \mathrm{C}$ ) to obtain higher extraction efficiency, thus some thermal degradations could occur, depending of the type of spice or herb. Also, the same authors reported that at higher temperature, namely $150{ }^{\circ} \mathrm{C}$ in the case of Laimanceae spices, the formation of Maillard reaction products may occur.

Table 1. Capsaicinoid concentration, total antioxidant activity (TAA) and quality indices (peroxide value, $\mathrm{K}_{232}$, $\mathrm{K}_{270}$ and $\Delta \mathrm{K}$ ) for olive oil and chili pepper aromatized olive oil (CPOO) at different concentrations of chili pepper (10 and $20 \% \mathrm{w} / \mathrm{w})$ produced by using traditional maceration (7 days) and ultrasound-assisted maceration at different times (10 and 20 minutes)

\begin{tabular}{|c|c|c|c|c|c|c|c|c|c|c|c|c|c|c|}
\hline \multirow[b]{3}{*}{ Capsaicin } & \multicolumn{2}{|c|}{ Olive oil } & \multicolumn{6}{|c|}{$10 \%$ CРОО } & \multicolumn{6}{|c|}{$20 \%$ СРОО } \\
\hline & & & \multicolumn{2}{|c|}{7 days } & \multicolumn{2}{|c|}{10 minutes } & \multicolumn{2}{|c|}{20 minutes } & \multicolumn{2}{|l|}{7 days } & \multicolumn{2}{|c|}{10 minutes } & \multicolumn{2}{|c|}{20 minutes } \\
\hline & & - & 123.8 & $\pm 6.4 \mathrm{a}$ & 84.6 & $\pm 3.9 \mathrm{~b}$ & 93.3 & $\pm 4.0 \mathrm{~b}$ & 221.0 & $\pm 10.7 \mathrm{c}$ & 114.7 & $\pm 5.8 \mathrm{a}$ & 169.9 & $\pm 6.8 \mathrm{~d}$ \\
\hline Hydrocapsaicin & & - & 56.5 & $\pm 3.8 \mathrm{a}$ & 39.1 & $\pm 2.45 \mathrm{~b}$ & 43.0 & $\pm 2.4 \mathrm{~b}$ & 103.2 & $\pm 6.6 \mathrm{c}$ & 53.2 & $\pm 3.0 \mathrm{a}$ & 83.0 & $\pm 3.8 \mathrm{~d}$ \\
\hline TAA & 3.09 & $\pm 0.1 \mathrm{a}$ & 18.0 & $\pm 1.3 \mathrm{~b}$ & 13.8 & $\pm 0.8 \mathrm{c}$ & 15.3 & $\pm 0.6 \mathrm{c}$ & 25.7 & $\pm 0.9 \mathrm{~d}$ & 17.1 & $\pm 0.9 \mathrm{~b}$ & 23.2 & $\pm 1.6 \mathrm{~d}$ \\
\hline Peroxide value & 3.5 & $\pm 1.0 \mathrm{a}$ & 6.8 & $\pm 1.1 \mathrm{~b}$ & 6.3 & $\pm 0.9 \mathrm{~b}$ & 5.5 & $\pm 0.4 \mathrm{~b}$ & 6.7 & $\pm 0.4 \mathrm{~b}$ & 7.8 & $\pm 1.6 \mathrm{~b}$ & 7.7 & $\pm 0.5 \mathrm{~b}$ \\
\hline $\mathrm{K}_{232}$ & 2.35 & $\pm 0.09 \mathrm{a}$ & 2.57 & $\pm 0.05 \mathrm{~b}$ & 2.74 & $\pm 0.09 \mathrm{~b}$ & 3.02 & $\pm 0.04 \mathrm{c}$ & 3.22 & $\pm 0.05 \mathrm{~d}$ & 2.96 & $\pm 0.05 \mathrm{e}, \mathrm{c}$ & 2.79 & $\pm 0.06 \mathrm{~b}$ \\
\hline $\mathrm{K}_{270}$ & 0.67 & $\pm 0.02 \mathrm{a}$ & 0.81 & $\pm 0.13 \mathrm{~b}$ & 0.94 & $\pm 0.05 \mathrm{~b}, \mathrm{c}$ & 0.97 & $\pm 0.02 \mathrm{c}$ & 1.05 & $\pm 0.02 \mathrm{~d}$ & 1.15 & $\pm 0.02 \mathrm{e}$ & 0.89 & $\pm 0.01 \mathrm{~b}$ \\
\hline$\Delta \mathrm{K}$ & 0.10 & $\pm 0.01 \mathrm{a}$ & 0.10 & $\pm 0.01 \mathrm{a}$ & 0.10 & $\pm 0.01 \mathrm{a}$ & 0.09 & $\pm 0.00 \mathrm{a}$ & 0.09 & $\pm 0.00 \mathrm{a}$ & 0.09 & $\pm 0.01 \mathrm{a}$ & 0.10 & $\pm 0.00 \mathrm{a}$ \\
\hline
\end{tabular}

a-e: different letters on the same line indicate significantly different values $(p<0.05)$.

Table 1 reports the quality indices for olive oil and CPOO samples by considering the traditional infusion and the UAE. With regard to the overall quality of olive oil, a higher peroxide value in the sample subjected to ultrasound for 20 minutes was observed, as well as higher values for the secondary oxidation indices $\left(\mathrm{K}_{232}\right.$ and $\mathrm{K}_{270}$ ), respect to 10 minutes of treatment. These results indicated a significant increase of the lipid oxidation by increasing the time of ultrasound-assisted extraction. This result could be explained by the possible degradation of some natural antioxidant in olive oil, such as polyphenols and tocopherols. On the other hand, an increase in total antioxidant activity was obtained in all case, respect to the unflavored olive oil. In particular, the highest antioxidant activity was recorded in traditionally macerated olive oil by using $20 \%$ chili pepper. By using the highest ultrasound-treatment time, the value of antioxidant activity reached those obtained for maceration during 7 days. The same trend, i.e. longer treatment times caused higher values for antioxidant activity, was also obtained for $10 \%$ chili pepper. 
Peroxide value was higher in all flavored olive oil, thus indicating a higher formation of primary oxidation products. No difference was found among infusion or ultrasound-treatment, both in 10 and 20 minutes. This results is probably explained by the higher release of bioactive compounds such as capsaicinoids, which acts as antioxidant, thus reducing olive oil oxidation. The same general trend was also observed for other quality indices such as $\mathrm{K}_{232}$ and $\mathrm{K}_{270}$. Some differences were explained by the presence in chili pepper of other compounds that could act as pro-oxidant (beta-carotene, vitamin $\mathrm{C}$, etc.), depending on the environment.

\subsection{Microwaves-Assisted Extraction}

The application of microwave-assisted extraction has been tested to speed up the process of flavoring. One of the first works was reported by Di Cesare et al. (1993), where the authors prepared garlic aromatized olive oil by comparing the performance of infusion, conventional heating and microwave treatments. They found that this latter technique had better performances than traditional maceration and conventional heating, both for the extraction of some volatile compounds and the stability indices.

According to Lucchesi et al. (2004), the spice used for the aromatization need to be dried in order to avoid the release of water that negatively affects olive oil quality and stability. Thus, only the use of dried chili pepper is recommended, and the use of fresh products should be avoided by producers or industry.

Other methods of extraction have been set up in the recent years, involving the use of microwave coupled with dry distillation at atmospheric pressure (Lucchesi et al., 2004). This method has been called "solvent-free microwave extraction" (SFME) and its efficiency has been tested and reported in literature for basil, mint and thyme, basically for their aromatic components. The method has been proposed for its advantages in terms of energy and time: in our extraction technology, we only used the first part of this process, which is the use of microwave to accelerate the release of non-volatile compounds from chili pepper, thus it seem to us ever more "green" and fast than other proposed techniques. In fact, in the case of SFME, the extraction of essential oils is based on the long heating of the spice and its distillation, to obtain the product that is subsequently added to a vegetable oil for its flavoring (Bayramoglu et al., 2008), whereas in our experiment, the olive oil was used as "extracting media".
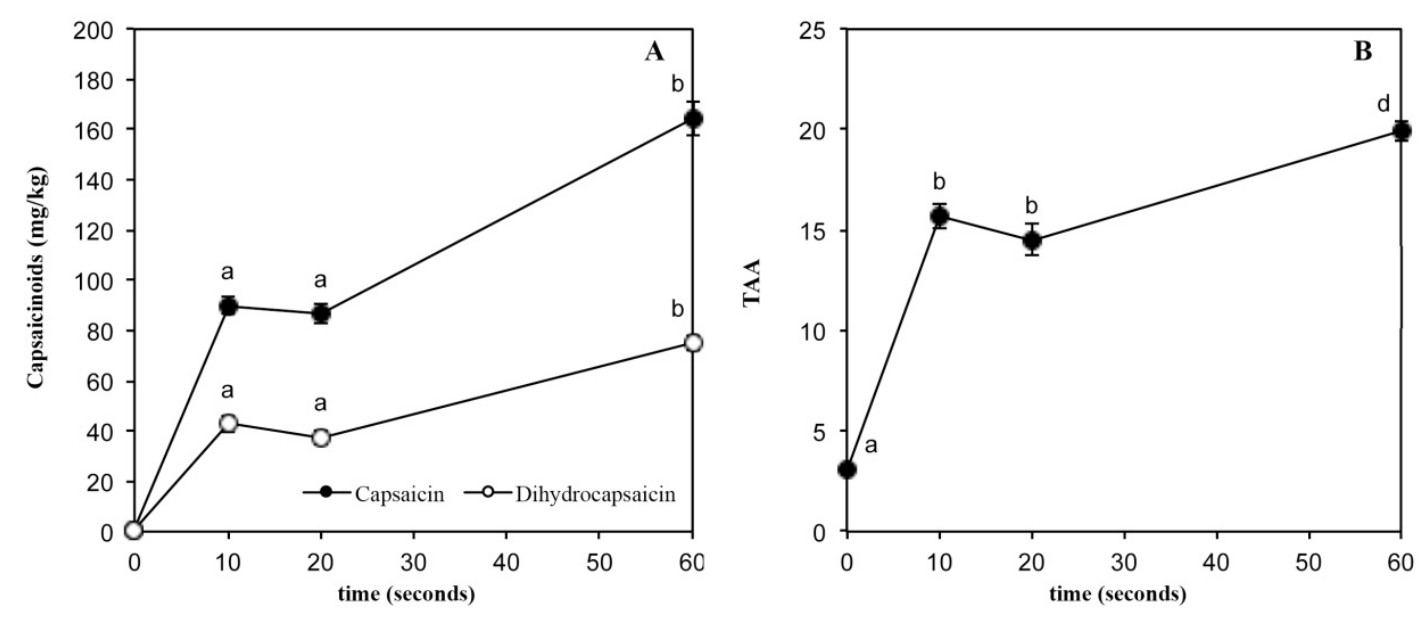

Figure 2. Capsaicinoids content (A) and antioxidant activity (B) in olive oil flavored with dried chili pepper (CPOO) by using $20 \%(\mathrm{w} / \mathrm{w})$ chili pepper and different times (10, 20 and 60 seconds) of microwave treatment

Capsaicinoids concentration (capsaicin and dihydrocapsaicin) in CPOO samples obtained by using microwaves treatment (MAE) resulted depended upon the treatment time of olive oil, as showed in Figure 2. The results indicate that a fast release of capsaicinoids is reached at 10 seconds of treatment; while in the following 10 seconds of heating no significant difference was obtained. At the end of the experiment, i.e. 60 seconds, a significant increase of capsaicinoids and antioxidant activity was obtained. This trend was probably explained by the different extractability of the chili compounds, on the basis of their higher or less retention in the chili pepper matrix, and also as affected by the gradient of concentration in the olive oil.

Also, these results have been explained by the acceleration of oxidative phenomena following the raising of the 
temperature in $\mathrm{CPOO}$, which increased from $26{ }^{\circ} \mathrm{C}$ to $34{ }^{\circ} \mathrm{C}$ in the sample treated for 10 seconds, from $26{ }^{\circ} \mathrm{C}$ to $70{ }^{\circ} \mathrm{C}$ in the sample treated for 30 seconds and from $26{ }^{\circ} \mathrm{C}$ to $76{ }^{\circ} \mathrm{C}$ in the sample treated for 60 seconds (data not shown). The quality indices for CPOO samples for microwave treatment showed a higher value of PV for samples added with $20 \%$ chili pepper.

Table 2. Capsaicinoids concentration, total antioxidant activity (TAA) and quality indices (peroxide value, $\mathrm{K}_{232}$, $\mathrm{K}_{270}$ and $\Delta \mathrm{K}$ ) for olive oil and chili pepper flavored olive oil (CPOO) produced by using 20\% (w/w) chili pepper produced by using microwave treatment at different times (10,30 and 60 seconds)

\begin{tabular}{lcccccccc}
\hline & \multicolumn{1}{l}{ Olive oil } & \multicolumn{6}{c}{ 20\% CPOO } \\
\cline { 3 - 9 } & & & 10 seconds & 30 seconds & 60 seconds \\
\hline Capsaicin & - & 89.8 & $\pm 3.5 \mathrm{a}$ & 86.7 & $\pm 3.7 \mathrm{a}$ & 164.7 & $\pm 6.9 \mathrm{~b}$ \\
Dihydrocapsaicin & & - & 42.7 & $\pm 3.0 \mathrm{a}$ & 37.6 & $\pm 2.9 \mathrm{a}$ & 75.1 & $\pm 3.3 \mathrm{~b}$ \\
TAA & 3.09 & $\pm 0.1 \mathrm{a}$ & 15.70 & $\pm 1.6 \mathrm{~b}$ & 13.91 & $\pm 1.8 \mathrm{~b}$ & 19.94 & $\pm 0.5 \mathrm{c}$ \\
Peroxide value & 3.50 & $\pm 1.0 \mathrm{a}$ & 6.50 & $\pm 0.6 \mathrm{~b}$ & 6.57 & $\pm 1.45 \mathrm{~b}$ & 9.25 & $\pm 0.3 \mathrm{c}$ \\
$\mathrm{K}_{232}$ & 2.35 & $\pm 0.09 \mathrm{a}$ & 2.71 & $\pm 0.05 \mathrm{~b}$ & 2.55 & $\pm 0.09 \mathrm{~b}$ & 2.74 & $\pm 0.25 \mathrm{~b}$ \\
$\mathrm{~K}_{270}$ & 0.67 & $\pm 0.02 \mathrm{a}$ & 0.83 & $\pm 0.02 \mathrm{~b}$ & 0.77 & $\pm 0.12 \mathrm{~b}$ & 0.85 & $\pm 0.01 \mathrm{~b}$ \\
$\Delta \mathrm{K}$ & 0.10 & $\pm 0.01 \mathrm{a}$ & 0.10 & $\pm 0.01 \mathrm{a}$ & 0.10 & $\pm 0.00 \mathrm{a}$ & 0.09 & $\pm 0.00 \mathrm{a}$ \\
\hline
\end{tabular}

a-c: different letters on the same line indicate significant different values $(p<0.05)$.

As reported in Table 2, total antioxidant activity dramatically increased respect to that found in unflavored olive oil, and the highest value was obtained for the longer treatment time. At the same time, an increase in peroxide value was observed, according to the extraction of some pro-oxidant compounds as previously discussed. The quality indices in flavored olive oil slightly but significantly changed as effected by heating: in particular, it has to be highlighted that in the specific case of our experiment the initial values for $\mathrm{K}_{232}$ and $\mathrm{K}_{270}$ were high, considering the limits for virgin olive oils (EU Reg. 2568/91). Thus, in the case of low quality olive oil, it is important for producers to strictly control the flavoring procedure to avoid excessive oxidation and very high (low quality) indices for lipid oxidation.

\section{Conclusions}

The accelerated methods for olive oil aromatization by addition of dried chili pepper allowed obtaining a flavored product by reducing the extraction time respect to the traditional maceration process. Ultrasound and microwaves treatments seem to be very effective, rapid and low-cost methods for the production of flavored olive oil, whereas the chemical indices of olive oil quality slightly changed as affected by the high temperature during treatment. On the other hand, one has to consider that methods involving the use of solvent for the extraction of capsaicinoids of other active compounds from spices and herbs are expensive, time-consuming and generally involve the use of toxic chemicals. Thus, our results suggest the application of direct extraction of chili pepper in the lipid phase at industrial level, as the method applied was effective and the final quality of flavored olive oil resulted satisfactory. This procedure also allows the production of a "green" flavored olive oil, avoiding the use of any petroleum solvent. Further work is needed by applying the same extraction procedure and using other kinds of spices, while other systematic studies will allow the definition of the extraction kinetic by considering the time and temperature during the process.

\section{Acknowledgements}

The research carried out was not supported by any specific grant or funding from public or private institutions. The authors declare that they have no conflict of interest. We thank Dr Alessandro Genovese for the critical discussion of our work.

\section{References}

Baiano, A., Terracone, C., Gambacorta, G., \& La Notte, E. (2009). Changes in Quality Indices, Phenolic Content and Antioxidant Activity of Flavored Olive Oils during Storage. Journal of American Oil Chemical Society, 86, 1083-1092. http://dx.doi.org/10.1007/s11746-009-1446-8

Bayramoglu, B., Sahin, S., \& Sumnu, G. (2008). Solvent-free microwave extraction of essential oil from oregano. 
Journal of Food Engineering, 88, 535-540. http://dx.doi.org/10.1016/j.jfoodeng.2008.03.015

Caporaso, N., Paduano, A., Nicoletti, G., \& Sacchi, R. (2013). Capsaicinoids, antioxidant activity, and volatile compounds in olive oil flavored with dried chili pepper (Capsicum annuum). European Journal of Lipid Science and Technology, 115(12), 1434-1442. http://dx.doi.org/10.1002/ejlt.201300158

Delazar, A., Nahar, L., Hamedeyazdan, S., \& Sarker, S. D. (2012). Microwave-assisted extraction in natural products isolation. Methods in Moleulcar Biology,

Di Cesare, I. F., Sansovini, G., Riva, M., \& Schiraldi, A. (1993). Influence of traditional and microwave technology on garlic sulphur compounds in garlic aromatized oils and on the stability of olive oil to oxidation, Industrie Alimentari, 32, 825-835.

EECR. (1991). European Economic Community Regulation 2568/91. Off J Eur Communities, L 248.

Falleh, H., Ksouri, E., Lucchesi, M. -E., Adbelly, C., \& Magné, C. (2012). Ultrasound-Assisted Extraction: Effect of Extraction Time and Solvent Power on the Levels of Polyphenols and Antioxidant Activity of Mesembryanthemum edule L. Aizoaceae Shoots. Tropical Journal of Pharmaceutical Research, 11(2), 243-249. http://dx.doi.org/10.4314/tjpr.v11i2.10

Hirasa, K., \& Takemasa, M. (1998). Spice science and technology. Marcel Dekker: New York. http://dx.doi.org/10.1116/1.590304

Hossain, M. B., Barry-Ryan, C., Martin-Diana, A. B., \& Brunton, N. P. (2011). Optimisation of accelerated solvent extraction of antioxidant compounds from rosemary (Rosmarinus officinalis L.), marjoram (Origanum majorana L.) and oregano (Origanum vulgare L.) using response surface methodology. Food Chemistry, 126, 339-346. http://dx.doi.org/10.1016/j.foodchem.2010.10.076

Hossain, M. B., Brunton, N. P., Patras, A., Tiwari, B., O'Donnell, C. P., Martin-Diana, A. B., \& Barry-Ryan, C. (2012). Optimization of ultrasound assisted extraction of antioxidant compounds from marjoram (Origanum majorana L.) using response surface methodology. Ultrasonic Sonochemistry, 12, 582-590. http://dx.doi.org/10.1016/j.ultsonch.2011.11.001

Kaefer, C. M., \& Milner, J. A. (2008). The role of herbs and spices in cancer prevention. Journal of Nutrition and Biochemistry, 19, 347-361. http://dx.doi.org/10.1016/j.jnutbio.2007.11.003

Korel, F., Bagdatlioglu, N., Balaban, M. O., \& Hisilg, Y. (2002). Ground Red Peppers: Capsaicinoids Content, Scoville Scores, and Discrimination by an Electronic Nose. Journal of Agricultural and Food Chemistry, 50, 3257-3261. http://dx.doi.org/10.1021/jf010537b

Lucchesi, M. E., Chemat, F., \& Madhya, J. (2004) Solvent-free microwave extraction of essential oil from aromatix herbs: comparison with conventional hydrodistillation. Journal of Chromatography A, 1043, 323-327. http://dx.doi.org/10.1016/j.chroma.2004.05.083

Lucchesi, M. E., Chemat, F., \& Smadja, J. (2004). An original solvent free microwave extraction of essential oils from spices. Flavour and Fragrance Journal, 19, 134-138. http://dx.doi.org/10.1002/ffj.1274

Maillard, M. N., Gianpaoli, P., \& Richard, H. M. J. (1997). Analysis of Eleven Capsaicinoids by Reversed-phase High Performance Liquid Chromatography. Flavor and Fragrance Journal, 12, 409-413. http://dx.doi.org/10.1002/(SICI)1099-1026(199711/12)12:6<409::AID-FFJ665>3.3.CO;2-C

Mandal, V., Mohan, Y., \& Hemalatha, S. (2007). Microwave Assisted Extraction - An Innovative and Promising Extraction Tool for Medicinal Plant Research. Pharmacognosy Reviews, 1(1), 7-18.

Peter, K. V. (2001). Introduction, in Handbook of Herbs and Spices. Woodhead Pubblishing Limited. In K. V. Peter (Ed.), vol 1. http://dx.doi.org/10.1533/9781855736450

Re, R., Pellegrini, N., Proteggente, A., Pannala, A., Yang, M., \& Rice-Evans, C. (1999). Antioxidant activity applying an improved ABTS radical cation decolorization assay. Free Radical Biology \& Medicine, 26 (9-10), 1231-1237. http://dx.doi.org/10.1016/S0891-5849(98)00315-3

Sanchez-Cabrera, Y., \& Pino, J. A. (2011). Headspace solid-phase microextraction analysis of volatile compounds from spice essential oils in dry flavourings. International Journal of Food Science \& Technology, 46(10), 2118-2123. http://dx.doi.org/10.1111/j.1365-2621.2011.02725.x

Souza, E. L., Stamford, T. L. M., Lima, E. O., \& Trajano, V. N. (2007). Effectiveness of Origanum vulgare L. essential oil to inhibit the growth of food spoiling yeasts. Food Control, 18, 409-413. http://dx.doi.org/10.1016/j.foodcont.2005.11.008 
Vazquez-Roncero, A. (1978). Les propietés de l'huile d'olive et leur influence sur les caracteristiques de l'huile. Revue Francais des Corps Gras, 25, 21-26.

Viellet, S., Tomao, V., \& Chemat, F. (2010). Ultrasound assisted maceration: An original procedure for direct aromatisation of olive oil with basil. Food Chemistry, 123, 905-911. http://dx.doi.org/10.1016/j.foodchem.2010.05.005

Vilkhu, K., Mawson, R., Simons, L., \& Bates, D. (2008). Applications and opportunities for ultrasound assisted extraction in the food industry - A review. Innovative Food Science and Emerging Technologies, 9(2), 161-169. http://dx.doi.org/10.1016/j.ifset.2007.04.014

Vinatoru, M. (2001). An overview of the ultrasonically assisted extraction of bioactive principles from herbs. Ultrasonics Sonochemistry, 8, 303-313. http://dx.doi.org/10.1016/S1350-4177(01)00071-2

Yamamoto, J., Yamada, K., Naemura, A., Yamashita, T., \& Arai, R. (2005). Testing various herbs for antithrombotic effect. Nutrition, 21, 580-587. http://dx.doi.org/10.1016/j.nut.2004.09.016

Yanishlieva, N. V., Marinova, E. M., \& Pokorny, J. (2006). Natural antioxidants from herbs and spices. European Journal of Lipid Science and Technolology, 108, 776-793. http://dx.doi.org/10.1002/ejlt.200600127

Ziino, M., Condurso, C., Vincenza Romeo, V., Tripodi, G., \& Verzera, A. (2009). Volatile compounds and capsaicinoid content of fresh hot peppers (Capsicum annuum L.) of different Calabrian varieties. Journal of the Science of Food and Agriculture, 89, 774-780. http://dx.doi.org/10.1002/jsfa.3511

\section{Copyrights}

Copyright for this article is retained by the author(s), with first publication rights granted to the journal.

This is an open-access article distributed under the terms and conditions of the Creative Commons Attribution license (http://creativecommons.org/licenses/by/3.0/). 